\title{
ETHNIC RESIDENTIAL CONCENTRATIONS IN UNITED STATES METROPOLITAN AREAS
}

\author{
JAMES P. ALLEN and EUGENE TURNER
}

\begin{abstract}
Although residential concentrations of immigrant ethnic groups in cities were common a century ago, it is not clear to what extent members of more recently arrived groups live near each other. We attempt to determine how common such clustered settlement is today, using 2000 census data to measure concentrations of Asians, Hispanics, and their larger ethnic subgroups in fifteen large metropolitan areas. The percentage of an ethnic group that is residentially concentrated correlated significantly with the group's proportion in an area. With metropolitan areas weighted equally, 38 percent of Hispanics and 13 percent of Asians were concentrated. However, when we analyzed eight specific nationality groups, the residentially concentrated proportion ranged from 14 to 59 percent. Level of cultural assimilation appears to explain group differences in level of concentration. Although ethnic concentrations were more pronounced in the largest metropolitan areas, important concentrations were also found in many of the smaller areas in our study. Keywords: enclaves, ethnic groups, immigrants, metropolitan areas, residential concentrations.
\end{abstract}

$\mathcal{A}$ round 1970, metropolitan areas in the United States began to receive increasing numbers of immigrants. However, little is known about the extent to which these immigrants, their U.S.-born children and grandchildren, and others with the same ethnic identity have clustered together to form neighborhood residential concentrations. We explore the extent to which ethnic groups are concentrated residentially in metropolitan areas and how groups and places vary in their levels of concentration.

Identifying and understanding such concentrations is important for three reasons. First, both assimilation theory and recent research suggest that the proportion of an ethnic group living in a concentrated settlement is an indicator of the group's relative cultural assimilation in the United States and, perhaps, its economic status (Massey 1985; Allen and Turner 1996; Alba and Nee 1999). The greater the proportion of the group that is residentially concentrated, the weaker the group's presumed assimilation. We probe this relationship by examining group differences in level of residential concentration and how they relate to the percentage of the group that is foreign-born and to the percentage that is proficient in English.

Thus, a group's settlement pattern can give a clue as to how its members are adapting to life in the United States. As phrased by other scholars studying immigrant suburbanization, "One important set of questions concerns the settlement patterns of immigrant groups within suburbia and, more specifically, the degree to which suburban settlement will result in ethnic concentrations . . . or dispersal in largely white communities" (Alba and others 1999, 458).

Second, a theoretical disagreement exists as to whether ethnic residential concentrations should even be found in modern metropolitan areas. If traditional as-

4. Dr. Allen and Dr. Turner are professors of geography at California State University, Northridge, California 91330. 
similation theory applies to recent immigrants, concentrations should be expected, at least as a stage in the process of adaptation. However, a contradictory view states that improved transportation, communication, and changes in lifestyle make ethnic concentrations unnecessary (Zelinsky and Lee 1998).

The third rationale for this analysis is that studies measuring ethnic residential concentrations have dealt only with the New York, Los Angeles, and San Francisco areas. Although concentrations are clearly evident in those places, the fact that these large places are among the largest receivers of immigrants clearly raises the question as to whether they are typical. To what extent are residential concentrations found in smaller metropolitan areas that have received fewer immigrants?

Why have residential concentrations-a possibly important component of the fabric of contemporary America-been so little investigated? One likely reason is that they are difficult to define. They are usually smaller than and independent of the municipal jurisdictions for which segregation indices based on census data are easily calculable. In addition, traditional theory based on the experience of the early twentieth century suggests that such concentrations should not be found in suburbs because the more assimilated immigrants should residentially disperse among the mostly white suburbanites. Assuming the theory to be correct, scholars may not even have looked for ethnic concentrations in suburbs.

\section{Residential Concentrations, Enclaves, and Ghettos}

Ethnic residential concentrations are neighborhoods in which members of ethnic groups live much closer to each other than would be the case if they were distributed randomly. The method by which such concentrations are defined is complex, and we explain it in detail below.

The concept of "enclave" can overlap with residential concentration, but we do not use that term in this research because it has multiple meanings that could make it potentially confusing. In the sense of residential concentrations, some scholars (Logan, Alba, and Zhang 2002; Poulsen, Johnston, and Forrest 2002; Parks 2004) have used "enclave" for neighborhoods in which the ethnic group is found in fairly high proportions, and Peter Marcuse (2000) stresses the voluntary nature of contemporary enclaves. On the other hand, when many scholars in sociology and geography refer to an "enclave" they mean an "ethnic-enclave economy." In that sense an enclave is a spatial concentration of ethnic businesses or their employees, particularly of employees in the same ethnic group as their employer (for example, Portes and Jensen 1987; Kaplan 1998; Zhou 2004). Larger ethnic residential concentrations are sometimes located near such business enclaves or other neighborhoods in which the institutions, social services, businesses, and professional offices of the ethnic group are focused. However, this is not always the case, and some of the smaller residential concentrations covered in our research may have no associated ethnic commercial or institutional area.

A "ghetto" is a type of residential concentration, but one produced by "restriction" on residential choice, whereas the term "ethnic concentration" implies essen- 
tially "voluntary" residential choices by members of a group. In the United States, black, Mexican, Puerto Rican, Chinese, Japanese, and Filipino ghettos were formed a half century or more ago when whites prevented most members of these groups from living outside certain neighborhoods.

American society has changed significantly since those days. Some residential concentrations of Asian and Hispanic groups began as ghettos (for example, Chinatowns, Little Manilas, barrios), but the majority of their current residents settled in them after 1970, exercising voluntary choice within the limits of available financial resources. Although the locational decision is usually to some extent constrained by other factors-limited financial resources, employment locations, or perhaps steering to certain neighborhoods by realtors-members of ethnic groups can essentially choose whether to live in or outside a concentration of their group.

The voluntary nature of modern residential decisions can be illustrated by the Chinese in New York City, many of whom were interviewed by the sociologist Min Zhou. Although Chinatown in Manhattan was established as a defensive bulwark against a hostile white society, by the late 1980 s that Chinatown and two others on Long Island were growing due to "voluntary segregation in order to preserve group solidarity for mutual help and for linguistic and cultural security. Today, the voluntary aspect of segregation has become more pronounced as the amount of hostility faced by immigrant groups has decreased. Also, the preference of immigrant Chinese for proximity and accessibility to the economic enclave largely determines their residential choices" (Zhou 1992, 215).

\section{Historical Ethnic Concentrations and Spatial Assimilation}

The large numbers of European immigrants who settled in America's cities between the 1860 s and the 1920 s represent our country's earlier period of large-scale immigration. The ethnic concentrations that developed a century ago in Chicago and other large U.S. cities received much attention from sociologists, particularly those at the University of Chicago. Their observations and understandings of immigrant settlement processes and patterns were later formalized into what is called "Immigrant Spatial Assimilation Theory" (Massey 1985; Alba and Nee 1999).

According to this theory, immigrants settle initially together and only assimilate spatially or disperse after they have become able to function culturally in American society and have achieved some economic success. A century ago most European immigrants arriving in large numbers came from rural areas, were poor and illiterate, and spoke little English. They could afford to live only in low-rent areas of cities. In such neighborhoods people of the same national origin often clustered together residentially for mutual support as they adjusted to urban America. These concentrations contained neighbors with whom the newcomers could easily talk, as well as familiar ethnic churches, food stores, and social organizations. They were often located near large factories or other major employers, accessible by walking or streetcar. Ethnic concentrations seemed to play a necessary role in the adaptation of most immigrants in cities at that time. But during the first half of the twentieth century, 
with increased economic success and acculturation to the English language and mainstream American culture, most of the children and grandchildren of immigrants dispersed into suburban areas, where the Euro-American or white population was dominant. Thus, spatial assimilation followed from cultural and economic assimilation.

Although Immigrant Spatial Assimilation Theory did not deal with ethnic proportions in the areas of concentration, historical evidence indicates that well-known ethnic neighborhoods were ethnically mixed. The leading ethnic group often comprised less than half the neighborhood's population. In 1910 Chicago, where ethnic concentrations were probably as pronounced as in any city, the majority of residents of the city's eleven Little Italys were not Italian, and only a third of the residents of Little Ireland were Irish (Philpott 1978, 141-142). Less than a third of the residents of German and Czech enclaves were German or Czech. Similarly, almost half the residents of neighborhoods described as "Little Polands" were not Polish, and 40 percent of Poles did not live in those "Polish" neighborhoods.

\section{Conflicting Theoretical Expectations}

To the extent that Immigrant Spatial Assimilation Theory remains valid, modern immigrants should still need to cluster residentially as a stage in their adaptation to this country. On the other hand, major transformations in cities, suburbs, employment, immigrant acceptance, and immigrants themselves over the last several decades suggest to some scholars that residential concentrations may no longer be necessary for immigrant adaptation in the post-1970 period (Zelinsky and Lee 1998; Alba and others 1999). We explain each of these two opposing expectations.

\section{REASONS FOR NOT EXPECTING RESIDENTIAL CONCENTRATIONS}

Since World War II urban centers have undergone substantial population growth and vast areal expansion. Manufacturing jobs in central-city industrial districts, which were once within walking distance of nearby ethnic concentrations, have generally disappeared or moved to distant suburbs. The more complex, service-based economy of today results in more varied employment opportunities for immigrants than were available a half century ago, and these are widely scattered across metropolitan areas. Automobiles, improved roads, and inexpensive and efficient means of communication diminish the advantages of residential concentration. Despite the expectation that residing in an ethnic concentration should improve employment opportunities, the opposite was demonstrated for Mexican and Vietnamese immigrant women in greater Los Angeles, presumably due to an oversupply of competitive labor in ethnic residential concentrations (Parks 2004).

Characteristics of recent immigrants have also changed. Many people who arrived in the United States during the last three decades have some English-language skills and advanced education. Some also bring substantial wealth with them, thus facilitating the purchase of homes and the development of new businesses. The more affluent newcomers are much freer to choose from a range of residential loca- 
tions than were immigrants a century ago, and many rent or buy homes in attractive neighborhoods soon after they arrive. Poorer immigrants settle in lower-cost housing. Their residential location decisions are not necessarily based on the presence of an ethnic concentration and institutions in the neighborhood. For these reasons an ethnic community can theoretically function and flourish without being geographically concentrated. Wilbur Zelinsky and Barrett Lee (1998) developed this idea most thoroughly and termed it "heterolocalism," to indicate that an ethnic community can be viable without being based on residential concentration.

\section{REASONS FOR EXPECTING RESIDENTIAL CONCENTRATIONS}

Although the argument that residential concentrations should not be necessary for the viability of modern ethnic communities seems reasonable, it may not be the entire story. Heterolocalism may not acknowledge sufficiently the importance of culture in some immigrants' lives, the relative comfort levels people feel in different neighborhoods, and the attractions to immigrants of an already developed concentration. Moreover, survey research from the Multi-City Study of Urban Inequality has shown that many Hispanics and Asians, as well as whites and blacks, have some preference for living near members of their own group and avoiding certain other groups (Bobo and others 2000, 182-194; Clark 2002). Such preferences tend to accentuate ethnic concentrations. Among Asians, the reputation of local public schools seems to be of particular importance in residential decision making, so that immigrants may concentrate residentially in preferred school districts.

Many larger residential concentrations include an ethnic economy in which business-owning members of the group employ others in the group. To illustrate, 40 percent of all the Chinese working in the cities of Monterey Park and Rosemead, in suburban Los Angeles, live in one of those two cities, and 78 percent of Chinese workers in those two cities live in the larger Chinese concentration that includes the two cities (Li 1998). Some immigrants who do not speak English well may locate in a residential concentration to be closer to jobs that do not require English, as in Manhattan's Chinatown, which contains some higher service-sector jobs for those immigrants who are educated and skilled but do not know English (Zhou 1992, 223). Residential proximity to ethnic shops, realtors, professional and health and social services, houses of worship, private schools, and other ethnic institutions is also desired by many immigrants.

A visible clustering of ethnic businesses and services also can symbolize and help publicize the group and serve as a community marker for political purposes (Hum and Zonta 2000, 208). Well-known ethnic concentrations can attract nonethnic customers to restaurants and other businesses located in those areas, thus helping the ethnic group economically.

People who anticipate prejudice and discrimination on the part of whites or others may see ethnic concentrations as havens from potential racist threats of all types. Among Chinese in New York, for example, "Within the enclave, racial/ethnic tensions are minimal, but outside it immigrant workers have to overcome presumed 
racism. In Chinatown the culture instills pride and confidence in individuals, thus building and strengthening ethnic identity and solidarity" (Zhou 1992, 224).

\section{THE EVIDENCE SO FAR}

Regardless of theory, the size of a residential concentration or its absence is most directly explained demographically by the size and direction of net ethnic-group movement into or out of a neighborhood. Such net movement results from the cumulative effect of countless individual and family decisions. If an ethnic group contains few people who clearly prefer to live near others in the group, formation of a residential concentration is unlikely. If one has already been established and its residents and new arrivals prefer to live there rather than outside it, the concentration will expand.

Ethnic residential concentrations have been measured in three of the largest metropolitan areas in the United States. Residential concentrations were found for several large immigrant groups in greater New York and Los Angeles (Logan, Alba, and Zhang 2002), and the characteristics of their residents were compared with those of members of the same group living outside concentrations. Maps also revealed numerous ethnic clusters in middle- and upper-income suburbs of Los Angeles (Allen and Turner 1997) as well as in poorer, central-city areas. Depending on the group and precisely how residential concentrations are defined, between about 25 percent and 60 percent of most group members in greater Los Angeles lived within these as of 2000 (Allen and Turner 2002). In San Francisco, contemporary residential concentrations for Mexican, Chinese, and Filipino immigrants were clearly present in 2000 (Pamuk 2004).

\section{Methodological Problems in Measuring Concentrations}

Measuring residential concentrations poses methodological challenges, which is a major reason for the lack of agreement as to how they should be delineated. One difficulty relates to the fact that concentrations can be viewed at various scales, each of which suggests different areal units of measurement.

\section{AREAL UNITS AND BOUNDARIES}

Concentrations can be measured in city blocks, where the proportion of the ethnic group may be much higher than if the larger areal unit of the census tract is used. To illustrate, some large block-level variations in ethnic proportions occur within the tracts of large Los Angeles concentrations, such as Koreatown and the Cambodian section of Long Beach (Allen and Turner 1995). Also, small concentrations located entirely within single apartment buildings (Allen and Turner 1997, 149, 158) can be identified with block-level data yet may be missed with larger areal units. However, our desire to avoid trivial concentrations with very small absolute populations suggests that a larger areal unit is better. For the present study, residential concentrations are appropriately measured in terms of census tracts, the areal unit preferred by most researchers for similar purposes. 
Another measurement problem is the frequently broad and complex transition zone between the central core of a concentration and its periphery. But some studies indicate that the specific boundary definition method may be less important than it appears. In research on the characteristics of residents of ethnic concentrations in greater Los Angeles and New York (Logan, Alba, and Zhang 2002), various criteria for defining residential concentrations were investigated. These included a minimum group representation of 10 percent in a neighborhood and a minimum group representation at five times the group's percentage in the metropolitan area. Differences in definition did affect the number of tracts identified as belonging to a concentration, because a few census tracts on the fringe of multitract concentrations dropped out when higher threshold definitions were used. However, findings regarding the characteristics of residents of ethnic concentrations were consistent regardless of definition.

Some scholars may think that ethnic residential concentrations must necessarily be areally extensive, perhaps composed of a minimum number of contiguous census tracts (Logan, Alba, and Zhang 2002; Pamuk 2004). But no theoretical reason for this exists. The method should measure only the degree to which members of the group locate in the same neighborhoods rather than in a dispersed or random pattern across the metropolitan area. A single census tract that meets the definition of a concentration should be as valid as a group of contiguous tracts. If the threshold definition is set high enough for random locational processes to seem insufficient as an explanation of the clustering, then the concentration presumably reflects the cumulative decisions of those who reside within it rather than some meaningless pattern.

\section{ALTERNATIVE METHODS OF MEASURING CONCENTRATIONS}

Measures of residential segregation between groups do not indicate the proportion of a group's population that is residentially concentrated (James and Taeuber 1985; White 1986; Massey and Denton 1988). This is because segregation statistics provide only a single summary measure of the distributional differences between groups rather than the level of residential concentration of a single group. One such statistic, the isolation index, varies as a function of the relative sizes of the groups being measured, which makes it inappropriate for the wide range of ethnic-group percentages that our study includes. The widely used index of dissimilarity is insensitive to differences in the level of neighborhood ethnic proportion above the ethnic proportion for the entire metropolitan area, which makes it of no value in measuring variations among areas with relatively high proportions of an ethnic group.

We tested a statistical package, GeoDa, that allowed us to identify large ethnic concentrations or clusters on the basis of similar ethnic proportions in contiguous tracts (Anselin 2005). The software calculated "local indicators of spatial association" and produced maps of ethnic clusters that were based on a computer algorithm rather than an arbitrarily chosen threshold percentage. However, the program omitted from the calculated clusters some tracts of exceptionally high ethnic percentage that were not adjacent to tracts with fairly similar high percentages. More- 
over, it resulted in the inclusion of a much larger number of tracts in the residential concentration than we ultimately found by our method. This suggested to us that the program would produce higher estimates of residentially concentrated populations than we thought appropriate.

Knowledge of the location and size of ethnic businesses and social and religious institutions might conceivably be used to identify concentrations and locate their cores, but such data are not readily available. Moreover, the degree of association between commercial and residential concentrations is not clear. Neither research nor scholarly consensus has established any minimum requirement of institutionssuch as food stores, places of religious worship, or ethnic social organizations-for viable group residential concentrations. Ethnic commercial centers may exist without residential concentrations, as appeared to be the case among Vietnamese in Northern Virginia (Wood 1997); and residential concentrations are not necessarily located near ethnic businesses or organizations.

\section{MEASURING CONCENTRATIONS BY ETHNIC-GROUP PERCENTAGE}

Although concentrations might have a certain minimum number of residents, research has not investigated such a threshold. Ethnic concentrations have been more commonly defined by some threshold percentage of the ethnic group within the areal unit. Some scholars may believe that a percentage threshold must be more than about 50 percent of a tract's population. However, both in the past and the present there was much ethnic residential mixing. This has been demonstrated for historical European immigrant concentrations in Chicago (Philpott 1978) and is true today, where large and well-known ethnic concentrations often constitute less than a majority of the total population ( $\mathrm{Li} 1998$ ).

In one recent study of the city of San Francisco an ethnic cluster was defined as a group of contiguous tracts, in each of which the group in question was represented in a proportion that was at least five percentage points higher than that in the city as a whole, with representation in at least one tract at ten percentage points above that in the city as a whole (Pamuk 2004). In other research (Hum and Zonta 2000) Asian Pacific American concentrations in the Los Angeles, San Francisco, Oakland, and New York Primary Metropolitan Statistical Areas (PMSAs) were defined by zip codes, in which the Asian Pacific American percentage was approximately twice that in the metropolitan area as a whole. Although the zip code is an appropriate areal unit, in our judgment this two-times percentage threshold is too low and results in overly extensive areas of concentration.

In earlier research we measured change between 1990 and 2000 in levels of residential concentration of ethnic groups in the Los Angeles Consolidated Metropolitan Statistical Area (CMSA) (Allen and Turner 2002). A concentration was defined as all tracts in which the group was represented at three times its metropolitan-wide percentage. Although that three-times threshold was reasonable for capturing change, a higher threshold may be preferable as a clearer indicator of nonrandom ethnic residential concentration for a single point in time. 
Other scholars have advocated measuring residential concentrations in terms of the percentage of the ethnic group living in neighborhoods (census tracts) in which the group is represented at or above a certain percentage threshold level that is kept constant for comparisons between groups and places (Poulsen, Johnston, and Forrest 2002). This seems appropriate for groups that comprise a fairly high proportion of the metropolitan population. They also recommended calculating group percentages at seven different thresholds, so that graphs can be constructed to compare the proportion of groups living in neighborhoods in which they are represented above each of the seven threshold values.

\section{Variables, Areas, and Groups Selected for This Research}

In this research we used two different files from the 2000 census. Residential concentrations and size of ethnic populations were measured with complete-count data (U.S. Census Bureau 2001) by a method explained below. We also explored how the demographic variables of ethnic-group size and proportion and two assimilation variables related to the level of residential concentration. To measure the level of cultural assimilation of groups in different places we used the percentage foreignborn and the percentage aged eighteen through sixty-four who spoke only English or spoke it very well. Those variables were chosen because Immigrant Spatial Assimilation Theory suggests that the percentage residentially concentrated should be directly related to the percentage foreign-born and inversely related to English-language proficiency. This is because groups with higher percentages of foreign-born may want to cluster residentially more because of less familiarity with the United States. On the other hand, groups with better knowledge of English may have less need to cluster because of their greater familiarity with this country's dominant language. To obtain these assimilation variables, it was necessary to use 16 percent sample data (U.S. Census Bureau 2003).

For our purposes it was important to investigate the possibility of concentrations across broadly defined metropolitan areas, in order not to overlook any concentrations in outer suburbs. Metropolitan Statistical Areas (MSAs) formed the regions in which we searched for ethnic concentrations. Where once-separate metropolitan areas coalesced, the CMSA was the relevant unit.

As of 2000, five cmsas in the United States-New York, Los Angeles, Chicago, Washington, D.C., and San Francisco-had populations of more than 7 million residents; our study included all five because they are places in which ethnic concentrations may be most important. For somewhat smaller places, we randomly selected urban areas from two additional size categories. Of the seventeen MSAs with between 2 million and 7 million residents, we sampled four: Houston, Texas; Cleveland, Ohio; Denver, Colorado; and Tampa, Florida. Of the twenty-seven metropolitan areas with populations of 1-2 million, we sampled six: Cincinnati, Ohio; San Antonio, Texas; Las Vegas, Nevada; Charlotte, North Carolina; New Orleans, Louisiana; and Grand Rapids, Michigan (Table I).

Within each of these fifteen CMSAs and MSAs, we measured concentrations separately for the total Hispanic and the total Asian populations and for their leading 
nationality groups. Only Asians reporting a single race were included, thus keeping the analysis much simpler than if multiracial Asians had been included. It was important to identify concentrations for specific nationalities because distinctive languages and cultures have been the main basis for forming a residential concentration. Because ethnic groups varied in their relative numbers from one metropolitan area to another, we measured concentrations for the three largest Asian groups and the two largest Hispanic groups in each area.

However, measuring panethnic Hispanic and Asian concentrations was a complementary part of our method. The larger numbers in these aggregations made possible some statistical analysis, and among the U.S.-born of these groups the tendency appears to be to self-identify more frequently as Asian or Hispanic-or Latino-than to name the specific national origin of the parents or grandparents (Espiritu 1992; Pew Hispanic Center 2004). In addition, for Hispanics the Spanish language and national cultures of the various ethnic groups are somewhat shared, resulting in some likely overlap in social networks and residential concentrations. In order not to overemphasize the role of the largest metropolitan areas, in our calculated averages for the fifteen areas we did not weight the means by population.

\section{Measuring Residential Concentrations}

We used two methods to measure the level of concentration, because the wide range in ethnic-group proportions made any one threshold definition unrealistic. At one extreme, Hispanics constituted more than 30 percent of the population of three metropolitan areas, and Asians represented more than 10 percent of residents in two metropolitan areas. On the other hand, nationality groups in many places numbered less than 5 percent of the total metropolitan population. After some experimentation with different thresholds to determine what levels of concentration would be unrealistic to expect, we chose two definitions.

\section{DEFINITION 1: FOR LOWER PERCENTAGE GROUPS, FIVE TIMES \\ THE METROPOLITAN-WIDE PERCENTAGE}

For groups representing less than 8 percent of the total population of a metropolitan area, the threshold for defining a residential concentration varied according to the group's percentage in the total population. A varying definition was chosen so that a residential concentration could be identified even if the group's percentage in the total tract population was quite low. Apart from differences in ethnic-group characteristics and assuming random group distributions, it would appear that the most important underlying factor behind varying ethnic percentages in tracts should be the group's percentage in the metropolitan area. The best way to control for that factor was a varying or sliding scale for defining the percentage threshold needed for a concentration.

We defined residential concentrations as including all census tracts in which the group was represented at five times its percentage in the entire metropolitan area. The use of this value-essentially a location quotient of five-had been used suc- 
Table I-Residential Concentrations of Hispanics and Asians in Fifteen U.S. Metropolitan Areas, 2000a

\begin{tabular}{|c|c|c|c|c|c|}
\hline $\begin{array}{c}\text { METROPOLITAN } \\
\text { AREA }\end{array}$ & $\begin{array}{c}\text { TOTAL } \\
\text { POPULATION }\end{array}$ & $\begin{array}{c}\text { HISPANICS } \\
\text { IN THE TOTAL } \\
\text { POPULATION } \\
(\%)\end{array}$ & $\begin{array}{c}\text { HISPANICS } \\
\text { RESIDENTIALLY } \\
\text { CONCENTRATED } \\
(\%)\end{array}$ & $\begin{array}{c}\text { ASIANS } \\
\text { IN THE TOTAL } \\
\text { POPULATION } \\
(\%)\end{array}$ & $\begin{array}{c}\text { ASIANS } \\
\text { RESIDENTIALLY } \\
\text { CONCENTRATED } \\
(\%)\end{array}$ \\
\hline New York & $21,199,865$ & 18.2 & 51.2 & 6.8 & 18.5 \\
\hline Los Angeles & $16,373,645$ & 40.3 & 74.3 & 10.7 & 23.7 \\
\hline Chicago & $9,157,540$ & 16.4 & 56.3 & 4.3 & 22.3 \\
\hline Washington & $7,608,070$ & 6.4 & 18.1 & 5.3 & 5.4 \\
\hline San Francisco & $7,039,362$ & 19.7 & 36.7 & 19.0 & 36.7 \\
\hline Houston & $4,669,571$ & 28.9 & 56.1 & 4.9 & 18.2 \\
\hline Cleveland & $2,945,831$ & 2.7 & 44.8 & 1.4 & 9.8 \\
\hline Denver & $2,581,506$ & 18.5 & 42.1 & 2.9 & 1.7 \\
\hline Tampa & $2,395,997$ & 10.4 & 17.6 & 1.9 & 2.8 \\
\hline Cincinnati & $1,979,202$ & 1.1 & 9.5 & 1.3 & 18.6 \\
\hline San Antonio & $1,592,383$ & 51.2 & 78.3 & 1.6 & 0.7 \\
\hline Las Vegas & $1,563,282$ & 20.6 & 35.7 & 5.2 & 1.0 \\
\hline Charlotte & $1,499,293$ & 5.1 & 14.3 & 1.9 & 1.2 \\
\hline New Orleans & $1,337,726$ & 4.4 & 5.7 & 2.2 & 22.8 \\
\hline Grand Rapids & $1,088,514$ & 6.3 & 23.9 & 1.6 & 16.5 \\
\hline Mean & & 16.7 & 37.6 & 4.7 & 13.3 \\
\hline
\end{tabular}

a Most metropolitan areas are CMSAS, which are identified by their largest city rather than their official name. Where groups constitute 8 percent or more of the total population, the percentage concentrated is the percentage in tracts more than 40 percent Hispanic or Asian. In all others, the percentage concentrated is calculated as the percentage living in tracts where the proportion of Hispanics or Asians is five times that of the metropolitan area as a whole. Means were not weighted by population.

Source: U.S. Census Bureau 2001.

cessfully and seemed sufficiently high to indicate meaningful, nonrandom concentrations (Logan, Alba, and Zhang 2002). Virginia Parks used the same five-times criterion in her research on the significance of residential concentration for employment (Parks 2004).

We are convinced that tracts identified by the five-times threshold reflect real decisions by members of the ethnic group to concentrate residentially or their shared locational preferences. However, the varying ethnic proportions represented in residential concentrations as defined by us suggest the need for caution in interpreting comparatively the meaning of the concentrations or the likelihood of associated ethnic institutions or businesses.

To eliminate from our analyses any groups so small that meaningful concentrations would be almost impossible to achieve, we arbitrarily established a bottom threshold of 1 percent of the total metropolitan population for a group's inclusion in our study. This threshold is the reason why our results for many metropolitan areas do not include each of the leading Hispanic or Asian nationality groups in those areas. Use of this threshold meant that each ethnic group in each metropolitan area comprised more than 14,000 persons, indicating that all measures of residential concentration in our study were based on nontrivial population numbers. 
Table II-Mean Levels of Residential Concentration and Characteristics of Hispanic, Asian, and Specific Nationality Groups in Fifteen U.S. Metropolitan Areas, $2000^{a}$

\begin{tabular}{lccc}
\hline Nesidentially & $\begin{array}{c}\text { Resionality Group } \\
\text { CONCENTRATED } \\
(\%)\end{array}$ & $\begin{array}{c}\text { FoREIGN-BORN } \\
(\%)\end{array}$ & $\begin{array}{c}\text { SPEAK ENGLISH ONLY } \\
\text { OR VERY WELL } \\
(\%)\end{array}$ \\
\hline Hispanic (15) & 37.6 & 50.0 & 56.3 \\
Mexican (11) & 59.4 & 50.5 & 44.5 \\
Central American (5) & 26.7 & 79.8 & 41.0 \\
Puerto Rican (4) & 32.7 & 44.3 & 71.3 \\
Asian (15) & 13.3 & 75.9 & 58.6 \\
Asian Indian (4) & 27.3 & 80.5 & 75.8 \\
Chinese (5) & 33.9 & 76.2 & 48.2 \\
Filipino (3) & 13.7 & 73.0 & 75.3 \\
Korean (2) & 33.3 & 81.5 & 40.0 \\
Vietnamese (3) & 42.5 & 77.0 & 35.7 \\
\hline
\end{tabular}

${ }^{a}$ The table is based on those metropolitan areas in which the ethnic group constituted at least 1 percent of the total CMSA or MSA population. The numbers in parentheses represent the number of metropolitan areas in which the given group qualified for these calculations. Means were calculated from values in Tables I, IV, and V, not weighted by population. Puerto Rican foreign-born includes those born in Puerto Rico. English profficiency was calculated only for those aged eighteen through sixty-four. The Dominican group is not shown because it was represented by only one case.

Sources: U.S. Census Bureau 2001, 2003.

DEFINITION 2: FOR HIGHER PERCENTAGE GROUPS, A 40 PERCENT THRESHOLD

For groups that constituted 8 percent or more of their metropolitan populations, concentrations were defined differently. They were considered to include all census tracts in which the group was represented at 40 percent or more of the total tract population. Our assessment of previous research was that this threshold was sufficient and appropriate-even for groups that comprised well over 10 or 15 percent of a metropolitan population. Michael Poulsen, Ron Johnston, and James Forrest (2002) graphed the cumulative percentages for Asians and Hispanics in the New York PMSA at different threshold values and found fairly consistent slopes, suggesting that groups would likely retain the relative importance of their concentration regardless of the threshold selected. The 40 percent threshold seemed appropriate because it minimized any break in measurements calculated by the two definitions for those groups comprising close to 8 percent of the total metropolitan populations. Thus, if an ethnic population constituted 8 percent of the total metropolitan population, application of the five-times method would result in the same 40 percent threshold used for higher percentage groups.

\section{Overall Levels of Group Concentrations}

With all metropolitan areas weighted equally, 38 percent of Hispanics and 13 percent of Asians were residentially concentrated (Table II). The high proportion of Hispanics who were residentially concentrated reflects a substantial overlapping of neighborhoods among the different Hispanic ethnic groups, including some na- 
tional groups not identified in our research. The much lower percentage of Asians residentially concentrated is partly explainable by the fact that the many Asian ethnic groups aggregated for the Asian concentration measure resulted in high thresholds for Asians, but the distinct cultures and social networks of each Asian nationality means that each developed largely separate concentrations. Thus, it is difficult for a threshold to be reached by the total Asian population. The 13 percent figure really indicates the importance of pan-Asian settlements or multiethnic Asian concentrations. These may occur most frequently where members of different Asian groups are attracted to similar suburbs, especially those with excellent schools. Such multiethnic Asian settlements may also be geographical indicators of the growing salience of a pan-Asian identity (Espiritu 1992).

On average a majority of Asians and Hispanics were living outside residential concentrations. This suggests the ability of immigrant communities to thrive while dispersed residentially, as stressed by Zelinsky and Lee (1998). However, it is possible that a large proportion of the ethnic group living outside concentrations are the U.S.-born children of immigrants, not immigrants themselves, together with immigrants who are well assimilated to the English language and U.S. culture.

Average levels of concentration for specific Hispanic and Asian nationality groups varied greatly (Table II), from Filipinos with less than 14 percent residentially concentrated to Mexicans, 59 percent of whom were concentrated. Means for specific Asian groups provided a better measure of concentrated settlement than did the 13 percent mean for the Asian aggregation because areas of concentration for those nationality groups typically did not overlap a great deal.

Theoretically, a higher percentage of a group living in residential concentrations should be associated with a higher percentage foreign-born, but, as Table II shows, this appears not to be the case. Although Filipinos were relatively low in both their level of concentration and their percentage foreign-born, as expected, Mexicans were much more highly concentrated than any other group but not high in percentage foreign-born. Moreover, Central Americans and Asian Indians were highest among the groups in their percentage foreign-born but relatively much lower in the percentage residentially concentrated.

We would also expect groups averaging higher levels of English-language proficiency among adults (aged eighteen through sixty-four) to be less residentially concentrated. This relationship is indeed suggested by our findings for Asian Indians, Chinese, and Puerto Ricans, compared with Vietnamese and Mexicans. The fact that Vietnamese had the highest level of concentration among Asian groups and were lowest in English proficiency is consistent with the greater adjustment difficulties many Vietnamese faced as refugees. Our findings regarding residential concentration and English-language skills are generally consistent with studies of Los Angeles, New York, and San Francisco, where residents of ethnic concentrations tended to be less assimilated to the mainstream United States culture than were members of the same groups living outside concentrations (Allen and Turner 1996; Logan, Alba, and Zhang 2002; Pamuk 2004). 
To better understand variations in levels of residential concentration among metropolitan areas, we calculated Pearson correlation coefficients between the percentages of Asians and Hispanics living in concentrations and possibly related variables for the fifteen areas (Table III). The small number of metropolitan areas for which we measured the various nationality group concentrations precluded us from a similar analysis of those groups.

The percentages of Hispanics and Asians in concentrations correlated highly with the percentage of the group in the total population. Thus knowing the percentage of either Hispanics or Asians in the local population provides a good indication of the relative level of concentration. If the .87 and .66 values of Pearson correlation coefficient are squared and given their appropriate interpretation, 76 percent of metropolitan differences in level of Hispanic residential concentration could be explained by varying Hispanic proportions, and 44 percent of metropolitan differences in Asian residential concentration could be explained by varying Asian proportions. Similarly, the greater the size of local Asian or Hispanic populations, the greater their residential concentration. It is not unreasonable to think that absolute size and proportion can be used to predict levels of concentration of other groups in other metropolitan areas, although the smallest metropolitan areas may have too few members of ethnic groups to form concentrations even if some wished to do so.

However, metropolitan population totals were not significantly related to the level of ethnic residential concentration. Thus, one should not assume that ethnic residential concentrations are more significant in the largest metropolitan areas. The insignificant correlations between levels of concentration and percentage foreign-born and percentage speaking English very well reflect differences between groups within the Asian and Hispanic aggregations, the complexity of influences affecting residential concentration, and the fact that the differences between metropolitan areas in any group's characteristics were typically very small.

The very low correlation, .08, between Asian and Hispanic concentrations indicates that one cannot assume that metropolitan areas in which one group has a high percentage of concentration will have either a similarly high or a complementarily low level of concentration for the other group. This result confirms the value of treating these two populations separately rather than combining them to examine residential concentrations in general.

\section{Residential Concentrations in Specific Places}

HISPANICS AND ASIANS

Consistent with the findings from correlation analysis, the proportionately larger Hispanic and Asian populations tended to have higher levels of residential concentration (Table I). Many of these represent the growth of concentrated settlements that formed before 1960 as ghettos, but their recent expansion reflects more the voluntary processes of developing concentrations. In addition, a shortage of financial resources still limits residential choice, particularly among recent Hispanics, as it did in the earlier period. 
Table III-Levels of Residential Concentration in Fifteen U.S. Metropolitan Areas, 2000: Selected Correlations

\begin{tabular}{lc}
\hline \hline GRoup & $\begin{array}{c}\text { PEARSON CORRELATION } \\
\text { COEFFICIENT }\end{array}$ \\
\hline Percentage of Hispanics living in concentrations, correlated with: & .46 \\
Total metropolitan population & $.63^{*}$ \\
Total Hispanic population & $.87^{* *}$ \\
Percentage of Hispanics in the total metropolitan population & -.45 \\
Percentage of Hispanics foreign-born (outside the fifty states) & .03 \\
Percentage of Hispanics speaking English only or very well & .08 \\
Percentage of Asians residentially concentrated & .42 \\
Percentage of Asians living in concentrations, correlated with: & $.61^{*}$ \\
Total metropolitan population & $.66^{* *}$ \\
Total Asian population & -.09 \\
Percentage of Asians in the total metropolitan population & -.24 \\
Percentage of Asians foreign-born & \\
Percentage of Asians speaking English only or very well & \\
\hline$* p<.05 * * p<.01$ & \\
Sources: U.S. Census Bureau 2001, 2003. &
\end{tabular}

For groups represented in lower proportions, the proportion of groups living in ethnic residential concentrations sometimes varied substantially among metropolitan areas. Nevertheless, for most places some ethnic-group members were clearly choosing to live in the same neighborhood as others in their group.

We illustrate the use of Tables I, IV, and V for New York and Cincinnati. In New York, Hispanics represented 18.2 percent of the total CMSA population, and 51.2 percent of Hispanics were living in census tracts that were 40 percent or more Hispanic. In Cincinnati, where Asians comprised only 1.3 percent of the metropolitan population, 18.6 percent of Asians lived in tracts that were more than 6.5 percent Asian (five times the metropolitan-wide 1.3 percent).

Because of our varying measure of residential concentration, metropolitan differences are most convincing when comparisons are made between places having similar proportions of a group and thus similar thresholds for defining concentrations. For example, Hispanics were residentially concentrated much more in Grand Rapids than in New Orleans. Asians in Cincinnati, New Orleans, and Grand Rapids had much higher levels of residential concentration than did Asians in Tampa, San Antonio, and Charlotte. Asians in New York were much more concentrated than were Asians in Washington.

\section{NATIONALITY GROUPS}

Place differences are also evident for nationality groups, including cases where groups comprised fairly similar proportions in the total population. In Tampa, the contrast in residential concentration between Mexicans and Puerto Ricans is striking. Central Americans were much more residentially concentrated in Washington than in Houston. Mexicans were more concentrated in San Francisco than in Denver or Las 
Table IV-Concentrations of Hispanic Nationality Groups in Selected U.S. Metropolitan Areas, 2000

\begin{tabular}{|c|c|c|c|}
\hline $\begin{array}{l}\text { NATIONALITY GROUP / } \\
\text { METROPOLITAN AREA }\end{array}$ & $\begin{array}{c}\text { TOTAL ETHNIC } \\
\text { POPULATION IN THE } \\
\text { METROPOLITAN AREA }\end{array}$ & $\begin{array}{c}\text { HISPANICS } \\
\text { IN THE TOTAL } \\
\text { POPULATION } \\
(\%)\end{array}$ & $\begin{array}{c}\text { HISPANICS } \\
\text { RESIDENTIALLY } \\
\text { CONCENTRATED } \\
(\%)\end{array}$ \\
\hline \multicolumn{4}{|l|}{ Mexican } \\
\hline Los Angeles & $4,962,046$ & 30.3 & 61.4 \\
\hline Chicago & $1,121,089$ & 12.2 & 45.3 \\
\hline Houston & 985,197 & 21.1 & 46.0 \\
\hline San Francisco & 981,311 & 12.2 & 45.3 \\
\hline San Antonio & 572,323 & 35.9 & 61.6 \\
\hline Denver & 312,598 & 12.1 & 29.6 \\
\hline Las Vegas & 232,145 & 14.8 & 29.1 \\
\hline Washington & 75,617 & 1.0 & 17.6 \\
\hline Tampa & 53,732 & 2.2 & 44.8 \\
\hline Grand Rapids & 46,942 & 4.3 & 26.5 \\
\hline Charlotte & 46,574 & 3.1 & 23.1 \\
\hline \multicolumn{4}{|l|}{ Central American } \\
\hline Houston & 886,227 & 1.8 & 10.6 \\
\hline Los Angeles & 262,904 & 2.7 & 32.2 \\
\hline Washington & 134,562 & 1.8 & 42.2 \\
\hline San Francisco & 100,853 & 1.4 & 25.0 \\
\hline New Orleans & 14,821 & 1.1 & 23.7 \\
\hline \multicolumn{4}{|l|}{ Puerto Rican } \\
\hline New York & $1,325,778$ & 6.3 & 20.5 \\
\hline Chicago & 164,509 & 1.8 & 45.0 \\
\hline Tampa & 75,621 & 3.2 & 2.9 \\
\hline Cleveland & 47,444 & 1.6 & 62.5 \\
\hline \multicolumn{4}{|l|}{ Dominican } \\
\hline New York & 551,538 & 2.6 & 48.2 \\
\hline
\end{tabular}

Source: U.S. Census Bureau 2001.

Vegas (Table IV). Asian Indians in Chicago were more concentrated residentially than were Asian Indians in Washington, despite similar proportions in their metropolitan areas (Table V). Similarly, Filipinos were more concentrated in Los Angeles than in Las Vegas. The substantial place variations in percentage residentially concentrated presumably result from the characteristics of the group, the spatial patterns of housing types and prices, and the social and economic context of the group's reception in specific metropolitan areas.

The actual numbers of people residentially concentrated may be larger than expected, especially where the group proportions in the metropolitan area were very low. For example, the residentially concentrated Central Americans in Houston numbered more than 9,000. Also, more than 15,000 Asian Indians were residentially concentrated in Houston, and Koreans and Chinese in Washington each had more than 16,000 members living in ethnic residential concentrations. When one remembers that these nontrivial numbers were established by means of a stringent 
Table V-Concentrations of Asian Nationality Groups in Selected U.S. Metropolitan Areas, 2000

\begin{tabular}{|c|c|c|c|}
\hline $\begin{array}{l}\text { NATIONALITY GROUP / } \\
\text { METROPOLITAN AREA }\end{array}$ & $\begin{array}{c}\text { TOTAL ETHNIC } \\
\text { POPULATION IN THE } \\
\text { METROPOLITAN AREA }\end{array}$ & $\begin{array}{c}\text { ASIANS } \\
\text { IN THE TOTAL } \\
\text { POPULATION } \\
(\%)\end{array}$ & $\begin{array}{c}\text { ASIANS } \\
\text { RESIDENTIALLY } \\
\text { CONCENTRATED } \\
(\%)\end{array}$ \\
\hline \multicolumn{4}{|l|}{ Asian Indian } \\
\hline New York & 400,194 & 1.9 & 28.9 \\
\hline Chicago & 116,868 & 1.3 & 37.1 \\
\hline Washington & 88,211 & 1.2 & 13.1 \\
\hline Houston & 51,959 & 1.1 & 29.9 \\
\hline \multicolumn{4}{|l|}{ Chinese } \\
\hline New York & 504,615 & 2.4 & 43.1 \\
\hline San Francisco & 470,705 & 6.7 & 18.4 \\
\hline Los Angeles & 414,582 & 2.5 & 51.7 \\
\hline Washington & 77,513 & 1.0 & 21.6 \\
\hline Houston & 48,537 & 1.0 & 34.8 \\
\hline \multicolumn{4}{|l|}{ Filipino } \\
\hline Los Angeles & 371,421 & 2.3 & 19.2 \\
\hline San Francisco & 323,606 & 4.6 & 22.4 \\
\hline Las Vegas & 33,558 & 2.1 & 0.0 \\
\hline \multicolumn{4}{|l|}{ Korean } \\
\hline Los Angeles & 252,975 & 1.6 & 42.9 \\
\hline Washington & 74,454 & 1.0 & 23.7 \\
\hline \multicolumn{4}{|l|}{ Vietnamese } \\
\hline San Francisco & 146,613 & 2.1 & 45.8 \\
\hline Houston & 63,924 & 1.4 & 33.0 \\
\hline New Orleans & 14,864 & 1.1 & 48.6 \\
\hline
\end{tabular}

Source: U.S. Census Bureau 2001.

criterion, it seems possible that our measurement of residentially concentrated ethnic populations underestimates the actual degree of ethnic clustering as perceived by ethnic-group members.

\section{The Varying Importance of Ethnic Residential Concentrations}

This is the first systematic comparative study of ethnic residential concentrations in a large number of metropolitan areas. Concentrations were defined by two methods, depending on the ethnic group's proportion in the metropolitan area. Both the 40 percent and the five-times criteria, also used by other scholars, are sufficiently high to indicate that members of the ethnic group were residing together for conscious, nonrandom reasons. Thus, even smaller concentrations representing low proportions of the group should represent meaningful shared preferences to members of the group.

Ethnic concentrations were found for most of the larger immigrant ethnic groups in most metropolitan areas with a population of more than 1 million. This indicates that they are widespread outside the very largest metropolitan areas and are an 
important part of ethnic-group settlement. Such concentrations are expected, according to Immigrant Spatial Assimilation Theory.

In contrast to the situation several decades ago, when members of many groups were prohibited from living outside certain areas (often called "ghettos"), members of contemporary immigrant ethnic groups have been essentially able to choose to live in a residential concentration of their group. Clearly, many members of ethnic groups find satisfaction in living close to others of their group. Despite the argument of heterolocalism that technological and other changes have diminished or even eliminated the need for ethnic residential clustering, our measurements have demonstrated that contemporary ethnic residential concentrations are alive and well.

However, the fact that most Hispanics and Asians did not live in ethnic residential concentrations also lends support to the notion of heterolocalism, in which contemporary immigrants are thought to be able to adapt successfully without forming residential concentrations. Clearly one should not assume that the majority of ethnic populations are residentially concentrated.

Ethnic groups differed in the relative importance of residential concentrations. Groups that were less proficient in English tended to have higher percentages of the group living in residential concentrations, a finding consistent with Immigrant Spatial Assimilation Theory.

The best indicator of the likely importance of ethnic concentrations is an ethnic group's percentage within the total metropolitan population. We found that varying Hispanic proportions explained 76 percent of metropolitan differences in Hispanic residential concentration levels. Similarly, 44 percent of metropolitan differences in Asian residential concentration could be explained by the varying Asian proportions in those areas.

Although ethnic residential concentrations tended to be more important in larger metropolitan areas, the correlation between metropolitan population size and the percentage of a group residentially concentrated was not significant. Because few studies exist of residential concentrations in places other than the largest immigrant gateway centers, our finding that such concentrations frequently appear in smaller metropolitan areas-those with a population of less than 3 million-is particularly significant. To illustrate, we point to Mexican concentrations in Tampa, Charlotte, Grand Rapids, and San Antonio, to the Puerto Rican concentration in Cleveland, and to the Central American and Vietnamese concentrations in New Orleans. These findings may prompt scholars to recognize that ethnic residential concentrations not known to them might exist in their own localities.

\section{REFERENCES}

Alba, R., and V. Nee. 1999. Rethinking Assimilation Theory for a New Era of Immigration. In The Handbook of International Migration: The American Experience, edited by C. Hirschman, P. Kasinitz, and J. DeWind, 137-161. New York: Russell Sage Foundation.

Alba, R., J. R. Logan, B. J. Stults, G. Marzan, and W. Zhang. 1999. Immigrant Groups in the Suburbs: A Reexamination of Suburbanization and Spatial Assimilation. American Sociological Review 64 (3): $446-460$. 
Allen, J. P., and E. Turner. 1995. Ethnic Differentiation by Blocks within Census Tracts. Urban Geography 16 (4): 344-364.

1996. Spatial Patterns of Immigrant Assimilation. Professional Geographer 48 (2): 140-155.

. 1997. The Ethnic Quilt: Population Diversity in Southern California. Northridge: California State University, Center for Geographical Studies.

- 2002. Changing Faces, Changing Places: Mapping Southern Californians. Northridge: California State University, Center for Geographical Studies.

Anselin, L. 2005. Exploring Spatial Data with GeoDa: A Workbook. Urbana: University of Illinois, Spatial Analysis Laboratory. [www.geoda.uiuc.edu/downloadin .php].

Bobo, L. D., M. L. Oliver, J. H. Johnson Jr., and A. Valenzuela Jr., eds. 200o. Prismatic Metropolis: Inequality in Los Angeles. New York: Russell Sage Foundation.

Clark, W. A. V. 2002. Ethnic Preferences and Ethnic Perceptions in Multi-Ethnic Settings. Urban Geography 23 (3): $237-256$.

Espiritu, Y. L. 1992. Asian American Panethnicity: Bridging Institutions and Identities. Philadelphia: Temple University Press.

Hum, T., and M. Zonta. 2000. Residential Patterns of Asian Pacific Americans. In Transforming Race Relations: The State of Asian Pacific America, edited by P. Ong, 191-242. Los Angeles: LEAP Asian Pacific American Public Policy Institute and UCLA Asian American Studies Center.

James, D. R., and K. E. Taeuber. 1985. Measures of Segregation. In Sociological Methodology 1985, edited by N. Tuma, 1-32. San Francisco: Jossey-Bass.

Kaplan, D. H. 1998. Geographical Aspects of Ethnic Economies. Urban Geography 19 (6): 487-488.

Li, W. 1998. Anatomy of a New Ethnic Settlement: The Chinese Ethnoburb in Los Angeles. Urban Studies 35 (3): 479-501.

Logan, J. R., R. D. Alba, and W. Zhang. 2002. Immigrant Enclaves and Ethnic Communities in New York and Los Angeles. American Sociological Review 67 (2): 299-322.

Marcuse, P. 2000. Cities in Quarters. In A Companion to the City, edited by G. Bridge and S. Watson, 270-281. Malden, Mass.: Blackwell Publishers.

Massey, D. S. 1985. Ethnic Residential Segregation: A Theoretical and Empirical Review. Sociology and Social Research 69 (3): 315-350.

Massey, D. S., and N. A. Denton. 1988. The Dimensions of Residential Segregation. Social Forces 67 (2): $281-315$.

Pamuk, A. 2004. Geography of Immigrant Clusters in Global Cities: A Case Study of San Francisco. International Journal of Urban and Regional Research 28 (2): 287-307.

Parks, V. 2004. Access to Work: The Effects of Spatial and Social Accessibility on Unemployment for Native-Born Black and Immigrant Women in Los Angeles. Economic Geography 80 (2): 141-172.

Pew Hispanic Center. 2004. 2002 National Survey of Latinos, including Survey Briefs. [http://pewhispanic .org/reports/report.php?ReportID $=15]$.

Philpott, T. L. 1978. The Slum and the Ghetto: Neighborhood Deterioration and Middle-Class Reform, Chicago, 1880-1930. New York: Oxford University Press.

Portes, A., and L. Jensen. 1987. What's an Ethnic Enclave? The Case for Conceptual Clarity. American Sociological Review 52 (6): 768-771.

Poulsen, M., R. Johnston, and J. Forrest. 2002. Plural Cities and Ethnic Enclaves: Introducing a Measurement Procedure for Comparative Study. International Journal of Urban and Regional Research $26(2): 229-243$.

U.S. Census Bureau. 2001. Census of Population and Housing, 2000. Summary File 1. [http://factfinder .census.gov].

- 2003. Census of Population and Housing, 2000. Summary File 4. [http://factfinder.census .gov].

White, M. J. 1986. Segregation and Diversity Measures in Population Distribution. Population Index $52(2): 198-221$.

Wood, J. 1997. Vietnamese American Place Making in Northern Virginia. Geographical Review 87 (1): $58-72$.

Zelinsky, W., and B. A. Lee. 1998. Heterolocalism: An Alternative Model of the Sociospatial Behaviour of Immigrant Ethnic Communities. International Journal of Population Geography 4 (4): 281-298.

Zhou, M. 1992. Chinatown: The Socioeconomic Potential of an Urban Enclave. Philadelphia: Temple University Press.

- 2004. Revisiting Ethnic Entrepreneurship: Convergencies, Controversies, and Conceptual Advancements. International Migration Review 38 (3): 1040-1074. 